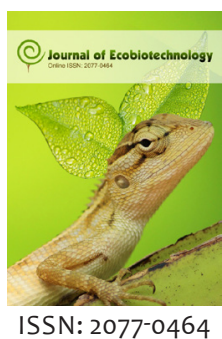

Received: August 13, 2020 Accepted: October 18, 2020 Published: October 22, 2020

*Corresponding Author: M. Manjur Shah, Email:mmanjurshah@gmail. com

\section{Control of filariasis vector using Ovillanta in Gwale local Government area of Kano State, Nigeria}

\author{
A. B. Umar, A. H. Dankaka and M. Manjur Shah* \\ Department of Biological Sciences, Yusuf Maitama Sule University, Kano, Nigeria
}

\begin{abstract}
The study was aimed at finding the effectiveness of a physical method of controlling filariasis vector larvae. Four ovillanta traps were placed in four different sites (north, south, west and east) of Gwale Local Government area of Kano state. The eggs and immature stage (larvae) of the filariasis vector were collected and destroyed. A total of 134667 larvae were collected altogether. $25 \%$ from site A, $23 \%$ from site B, $28 \%$ from site C and 24\% from site D.The finding of the study shows that ovillanta trap is an effective method in controlling filariasis vector.
\end{abstract}

KEYWORDS: Culex larvae, Filariasis, Ovillanta, vector

\section{INTRODUCTION}

Culex mosquito commonly known as the "southern house mosquito" is a medium-sized brown mosquito that exists throughout the tropics and the lower latitudes of temperate regions. This species is found in the southern United States and is present throughout Florida. In Nigeria they are found in several areas such as Kano, Akure, Ondo, Ibadan and Edo [1]. This night time-active, opportunistic blood feeder is a vector of many pathogens, several of which affect humans.Culex mosquitoes are the chief vectors of Wuchereria bancrofti that cause a disease known as bancroftian filariasis [2]. Culex mosquitomay also cause protozoan, viral, parasitic and helminthic diseases.

Lymphatic filariasis stands next to malaria as the most important vector-borne disease in India. Culex quinquefasciatus (Cx. quinquefasciatus), a vector of lymphatic filariasis affects 119 million people living in 73 countries, with India accounting for $40 \%$ of the global prevalence of infection[3]. Japanese encephalitis (JE) a mosquito-borne viral disease is a serious public health problem in Asia [4] and it is highly endemic in few districts of Tamil Nadu, Southern India. To prevent mosquito- borne diseases and improve public health, it is necessary to control them. Malaria and filarial vectors in Nigeria are resistant to dichlorodiphenyltrichloroethane (DDT), hexachlorocyclohexane $(\mathrm{HCH})$, malathion, and deltamethrin [5]. In this situation, the change of insecticides has hampered the program with increased costs. Thus, the future of vector control mainly relies on the strategies for the management of existing insecticide resistance in the vectors and to limit its further spread. Therefore, it is the hour to launch extensive search to explore eco-friendly biological materials for control [6].

\section{MATERIAL AND METHODS}

\section{Sample Area}

Kano is the largest city in the Sudan Region of Nigeria. It is located between latitude $12^{\circ} 25$ to $12^{\circ} 40 \mathrm{~N}$ and longitude $8^{\circ} 35 \mathrm{~N}$ to $8^{\circ} 45 \mathrm{E}$. Kano city has for centuries been the most important commercial and industrial nerve centre of Northern Nigeria attracting millions from all parts of the country and beyond. Immigration and natural growth rate of $3 \%$ is expected to continue to increase the population and waste stream in the years to come. With a population presently estimated at 3.5 million, Kano metropolis is among the fastest growing cities in Nigeria. With a population density of about 1000 inhabitants per $\mathrm{km}^{2}$ within the Kano closed settled zone compared to the national average of 267 inhabitants per $\mathrm{km}^{2}$. It is also one of the most crowded. The city also has a large migrant worker population which has been increasing at the rate of 30 to 40 per cent per annum.

Gwale Local Government area was chosen and a total of four siteswere randomly selected from north, south, west and east area to constitute the Sampling Areas. Each site was labeled.

\section{OVILLANTA SET UP}

Ovillanta was created from two $50 \mathrm{~cm}$ sections of an old car tire, fashioned into a mouth-like shape, with a fluid release valve at 
the bottom. Inside the lower tire cavity, a milk-based, non-toxic solution was developed. Inserted to float in the artificial pond was a wooden or paper strip on which the female insect lays her eggs. The strip was removed twice weekly.

The solution, which now includes mosquito pheromone (the female insect's chemical perfume that helps others identify a safe breeding site)was drained, filtered, and recycled back into the tire. The pheromone was concentrates over time, making the ovillanta even more attractive for mosquitoes [7].

\section{COLLECTION OF LARVAE}

Culex mosquitoe larvae were collected twice weekly using filtering method as described by Gerardo et al. 2016 [8]. This was done by placing the kitchen filter on top of a clean plastic bottle of more than 2 litres. By opening the valve on the trap the water was drained at the centre of the filter and the larvae was retain as the water flow through the filter. The filter was removed containing larvae from the bottle and the valve was closed so as to replace the water. The number of larvae in each trap was counted and recorded, then poured into white plastic containers (Table 1).

\section{Identification of Filariasis Vector Larvae}

The filariasis vector larvae were identified by their simple morphological features as well as their behavior in water according to Linton et al. 2001 [9]. The larval head is short and stout, becoming darker toward the base. The mouth brushes have long yellow filaments that are used for filtering organic materials. The abdomen consists of eight segments, siphon, and saddle. Each segment has a unique setae pattern. The larvae of Culex mosquito tend to position themselves at an angle due to presence of siphon in which they use for respiration [10].

\section{Destruction of Filariasis Vector}

The filariasis vector larvae were destroyed using concentrated 70-80\% ethanol as described by [11].

\section{SCOPE OF THE STUDY}

Culex mosquitoes was collected twice weekly for period of eight months from January 2018 to September 2018, using Ovillanta

\section{RESULTS}

A total of 134667 filariasis vector larvae were collected from the four sites in Gwale Local Government area of Kano state. 25\% from site A, 23\% from site B, $28 \%$ from site C and 24\% from site D (Table 2).

During the first week of sample collection, small dark spots were observed on the top of the landing strip in all of the ovillanta traps. The presence of dark spots which later developed into Culex mosquito larvae after three days indicated the dark spots where the eggs were laid by the adult female culicine mosquito
Table 1: Sampling sites

\begin{tabular}{ll}
\hline SITE & Labeled \\
\hline GWALE NORTH & A \\
GWALE WEST & B \\
GWALE EAST & C \\
GWALE SOUTH & D \\
\hline
\end{tabular}

Table 2: Monthly numbers of culex larvae caught in each site

\begin{tabular}{lcccc}
\hline Month & Site A & Site B & Site C & Site D \\
\hline January & 2296 & 1976 & 2310 & 2101 \\
Febuary & 2548 & 2001 & 2452 & 2458 \\
March & 2601 & 2203 & 2710 & 2415 \\
April & 3101 & 2801 & 3204 & 3105 \\
May & 3001 & 2934 & 3292 & 3115 \\
June & 3521 & 3052 & 3537 & 3431 \\
July & 3982 & 3450 & 3841 & 3615 \\
August & 4021 & 3854 & 4003 & 4013 \\
September & 4321 & 4031 & 4201 & 4215 \\
October & 4601 & 4131 & 4701 & 4321 \\
& 33993 & 30429 & 37455 & 32790 \\
\hline
\end{tabular}

which was in accordance with Bates, 1949 [12].He stated that eggs are laid in raft which float on the surface of water and become darken after few hours of deposition that normally hatched within 24-30 hours.

The number of Culex mosquito larval instars collected from four ovillanta traps shows the effectiveness of the trap as a new technique of targeting the immatured stage of filariasis vector larvae which was in line with Lee et al. 1989 [13].observations which stated that Culex mosquito breeds in man-made artificial container such as septic tanks, stock draining tought, oxidation pond and tyres. The increase in number of the mosquito larvae in the trap may be due to re-used of the water rather than discarding as the mosquito released oviposition pheromones when they lay eggs which is in accordance with Gerardo et al. 2016 finding [8].

\section{CONCLUSION}

The findings of the study shows that, ovillanta trap is an effective trap which when placed in close proximity can be used to target the immature stage of filariasis vector larvae and destructing them might reduce the rate of transmission.

\section{REFERENCES}

1. Hotez, P. J., Asojo, O. A. and Adesino, A. M. "Zero ground" for the high prevalence neglated tropical diseases. Plots Negl Trop Dis. 2012:6(7):e1600.

2. Abdel-Hameed, A.A., Dura, W.T. and Alkhalife, I.S. An inguinal mass with local vascular lesions induced by a lymphatic filaria. Saudi Medical Journal, 2004;25:1106-1108.

3. Ramaiah, K.D., Das, P.K., Michael, E. and Guyatt H. The economic burden of lymphatic filariasis in India. ParasitolToday, 2000;16: 251-253.

4. Libraty, D.H., Nisalak, A., Endy, T.P., Suntayakorn, S., Vaughn, D.W. and Innis, B.L.(). Clinical and Immunological risk factors for severe disease in Japanese encephalitis. Trans R Soc Trop Med Hyg 2002;96:173-8.

5. Ravi, V., Vanajakshi, S., Gowda, A. and Chandramuki, A. A laboratory diagnosis of Japanese encephalitis using monoclonal antibodies and 
correlation of findings with the outcome. J Med Virol., 1989;29:221-3.

6. Raghavendra, K. and Subbarao, S.K. Chemical insecticides in malaria vector control in India. ICMR Bull, 2002;32: 1-7.

7. Hwag, Y. S., Kramer, W. I. and Mulla, M. S. Oviposition Attractants and Repellents of Mosquitoes.Isolation and Identification of Oviposition repellents for Culex Mosquitoes. J Chem Ecol., 1980;6:71-80.

8. Gerardo, U. C., Jonathan, M. H. and Colton, Y. M. "Canadian mosquito trap offers hope in fight against zika spread". Medical and Veterinary Entomology, 2016;17: 195-204.

9. Linton, Y. M., Harbach, R. E., Chang, M.S., Anthony T.G. and Matusop A. Mophological and Molecular identity of anopheles (Diptera: culicidae) the nominotypical member of a malaria vector species complex in South Asia. Systentomo, 2001;26:357-366.

10. Sirivanakarn, S. and White, G. B. (). Neotype designation of Culex quinquefasciatus Say (Diptera: Culicidae). Proceedings of the Entomological Society of Washington 80,360-372.

11. Schauff, M. E.Collecting and preserving insects and mites. USDA miscellaneous publication. 1986;1443: $68 \mathrm{Pp}$

12. Bates, M. The Natural History of Mosquitoes. Macmillian Company. New York, NY. 1949;379 pp.

13. Lee, D.J., Hicks, M. M., Debenham, M.L., Griffiths, M., Marks, E.N., Bryan, J.H. and Russell, R.C. The culicidae of the Australian region, volume 7. Canberra, Australia; Australian government publishing service 1989;281 pp. 